\title{
GRAMMATICAL ERROS COMMITED BY JUNIOR HIGH SCHOOL STUDENTS IN SPEAKING ENGLISH
}

\author{
Anggana, I.P.S. \\ English Language Education, Faculty of Language and Art \\ Ganesha University of Education \\ Singaraja, Indonesia \\ Email:
}

\begin{abstract}
The purposes of this study are to analyze the types of grammatical errors and to know the types of grammatical error which are frequently made by the junior high school students in speaking English. The research design in this study was descriptive qualitative design with the eighth grade students in second semester of SMP Negeri 4 Singaraja as the population and 33 students were chosen to be the sample. The instruments that were used to collect the data were researcher and video recorder. The result showed that students made error in omission, addition, misinformation, and misordering. The total of errors reaches 61 times. The highest frequency of error is omission which is $62.30 \%$. The second frequency of error is misordering, $18,4 \%$. The third frequency of error is addition which is $14,75 \%$. The last frequency of error is misformation that is $4,91 \%$.
\end{abstract}

Keywords: Grammatical error, Speaking

\section{INTRODUCTION}

English is one of the important language all over the world. English becomes more important because, nowadays, most of the countries in the world use English as foreign and the second language. Indonesia uses English as the foreign language so English is taught in the school starts from Elementary School, Junior High School until higher Education.

For many second languages or foreign language learners, the main priority of learning English is to master the ability to speak in English (Richards, 2008). Cameron (2001) argued that Speaking is a way of expressing meaning to others using an active language so that others can understand it. In simple way, speaking skill is the most important skill that should be mastered by the student in learning English as foreign language. By mastering speaking skill, students can express their feeling and ideas to other. Moreover, Richard (2010) Students can convey their ideas and information to others, and maintain social relationships by communicating with others by speaking. It can be said that by mastering speaking students can have good relationship with their environment. In learning a second or foreign language, speaking is the most important aspect. The success can be measured through students' or learners' skill in carrying out a conversation and interacting orally in that language (Nunan, 1999). Therefore, the students will use this skill if they want to express everything that they have in their mind. Human speak to tell people about their wishes, intentions, or needs. Therefore, the correct way of speaking will make sure the success of interaction among people.

Junior High School curriculum emphasizes the teaching of English integrated through the four language skills. They are speaking, listening, reading, and writing. This curriculum also emphasis that teaching English as foreign language should be based on the communication approach. This approach is based on the teaching of the language as a means of communication. Based on the interview to the student of SMP Negeri 4 Singaraja, students are not interesting in studying English because they think that English is difficult, especially in speaking. Their lack of vocabulary, grammar rule knowledge, and worry to make mistakes become the problems in their speaking. They tended to keep silent and even avoided talking or being asked by the teacher. They said that English is difficult and very complicated because the material used were not interesting and the material were also difficult to understand by the students. So they felt difficult to create their idea to speak up. The students at SMP Negeri 4 Singaraja were still unable to produce English during the English session, only few of them were able to do so. Majority of students cannot speak the language because of satisfactory with language learning among the students and their teachers. It can be concluded that, their knowledge were limited about vocabulary, grammatical, pronunciation, and fluency. 
Yorkey (1990) explained like the other skill, speaking skill is a skill that must be practiced continuously. So, speaking is skill that can make the students try to be a good speaker in order to make the listener understand what they are talking about. To be a good speaker is not as simple as other skills, students need to practice it continuously to make sure they can be a good speaker. Speaking is a productive language skill and receptive comprehension skills that involves a two-way process between the speaker and the listener (Byrne, 1997). Widdowson (1995) explained that Speaking involves both the receptive process like the acceptance of the language codes that are conveyed for the recipient to be understood, and participation. That means speaking skill is very important to be mastered by the students in order to make the students easier to communicate with other.

Speaking is not simply expressing something orally. However, there are some speaking aspects that students need to acquire to have a good speaking skill, namely: pronunciation, fluency, and accuracy (Brown: 2001; Hughes: 1989). As one of aspects that should be considered in speaking, grammatical competence becomes a part of the communicative competence (Lock, 1996). Grammar is one of the most difficult part in a language use. The Indonesian and English grammar have different grammatical rules. In learning English, the differences between the Indonesian and English grammar usually induce problem. Hornby (1987) explained that grammatical study is the study of the structural rules governing the composition of clauses, phrases, and words in a specific natural language. The term also refers to the study of the rule, and this field includes phonology, morphology, and syntax, often with phonetics, semantics, and pragmatics, aimed at assisting students in grammatical mastery is to make clear communication.

There are some reasons why grammar is very important. The first, grammar is very important because it may help enhancing accuracy. Marcel (1853) explains how grammar can help to develop accuracy in communication as "shaping the mind into a habit of order and clarity, along with logic and rhetoric, this accustoms the learner to the accuracy of the language, and hence the accuracy of thought". It means the rules of grammar can help learners to develop a habit of thinking logically and clearly. Therefore, after studying grammar, they will become more accurate when using the language. The second is by using proper grammar, we can show the sign of respect, both for the listener and the speaker (Clark, 2010). For the speakers, speaking clearly means they will get a good impression from the listeners and for the person with a poor grammar skill can form negative impression on the first time meeting and this may last for a long time. For listeners, a proper use of grammar shows that their thought is concerned. Speakers do not want them to waste time trying to figure out what they are saying.

Looking at the importance of grammar, especially in speaking English, the researcher was interested in analyzing the grammar error in speaking. There are two studies about grammatical error in speaking, the first research was done by Danurwindo (2014) showed that, students made error in omission, addition, misinformation, and misordering. The total of errors reaches 36 times in the students speaking consist of using simple present tense and simple past tense. The second research was done by Abdul (2008) the result of his study shows that there is error on students' pronunciation at segmental phonemes at final consonant due to the students' did not know the correct transcription and lack of practice pronouncing words. In this research the purpose of this study is to know the error in speaking that made by the student in eight grade use surface structure taxonomy by Dulay, Burt and Krashen (1982).

\section{METHODS}

The research was a qualitative research the data were collected in the form of word rather than numbers. In this study, descriptive data were presented to classify and investigate the grammatical errors in English speaking eight grade students in SMP 4 Singaraja. The analysis of the study was basically interpreting data obtained from English speaking of eight grade students in SMP 4 Singaraja. The object of the research was the grammatical errors in English speaking. While the subject was students of eight grade students of SMP 4 Singaraja academic year 2015/2016.

This research used 2 sources of data, primary and secondary data. Primary data is the data obtained from recording the statement or utterances done by the students. The secondary data used in this research are literature, library books, documents, archives, and descriptions other than grammatical error in speaking. The instruments that were used in this study were video recorder and the researcher. Descriptive analysis was used in this study where interpretation and conclusion were determind after 
collecting important information, fact and phenomena under study (Moleong, 2009). In this study after collecting data the researcher analyzed and interpreted the data descriptively.

The process of data collection in this study employed some steps. Step 1 is collecting data, the data were collected by recording the students' speaking to find there were some error or not, from the beginning until the end. Step 2 is identifying data, Identification of error by underlying the error the student's made. After recording the students' speaking, it would be continued by transcribing the record into the written text in order to make easier in identifying the error. The written text would be checked to find the error by underlying the error made by the students. Step 3 Classifying the error, after the error made by the students had been identified, it procees to the next step by grouping them into the type of error whether omission, addition, misordering or misformation. Step 4 is explaining the error, after grouping the error, they will be explained by establishing the source of the error and calculating how often the error appears. Step 5 is evaluating the error, evaluating error step involves putting the error in table and drawing conclusion referring to steps of error analysis method above

\section{RESULT AND DISCUSSION}

The data was taken from 33 students (12 male, 21 female) VIII A1 of SMP N 4 Singaraja in the academic year 2015/2016. The data was recorded and transcribed into written text. After getting all the statements from the students by recording, it was continued by describing them into written texts. It was found that there were 115 statements made by the students. After transcribing the oral statements into the written text, the next step is identifying the error that was done by the students. From the written text, the next steps is identifying the error by underlying the error. From 115 statements produced by the students, 61 statements or $63 \%$ were categorized as error. After identifying them, the error were classified and analyzed using the surface structure taxonomy by Dulay, et.al (1982). The error were classified into 4, they are omission, assition, misordering, and misformation. The detail result can be seen in table 1 .

Table 1. Errors Commited by Students

\begin{tabular}{cccc}
\hline No & Type of Error & Total Error & Percentage \\
\hline 1 & Ommition & 38 & $62,30 \%$ \\
2 & Addition & 9 & $14,75 \%$ \\
3 & Misformation & 3 & $4,91 \%$ \\
4 & Misordering & 11 & $18,04 \%$ \\
& Total & 61 & $100 \%$ \\
\hline
\end{tabular}

\section{Omission error}

Students tend to omit function words rather than content words. It is characterized by the absence of an item that must appear in the well-formed utterance. The researcher found that from 61 statements made by the student, there were 38 statements that were categorized as omission error. The result showed that the student have problems in the use of 'to be' and the use of article 'a and an'. Here are several examples of the error made by the students. The error omission are symbolized by giving underlying the errors.

1. I think physical exercise _ difficult because I hate that

2. What _ you think about Agung dika?

3. I think Gung dika is _ handsome boy

4. We can understand _ easily

5. He can drink _ glass of milk

From the sentences above, it can be seen clearly that those sentences are incorrect. In the first sentence "I think physical exercise_difficult because I hate that" there is an error commited because the student did not put 'is' after mentioning adjective (exercise). The next sentence is "What you think about Agung dika?". This sentence is incorrect because there is a missing word, the student did not put 'do' when asking a question."I think gung dika is handsome boy" is the third example. This sentence is incorrect because there is a missing part in the sentence, the student forgot the use of article ' $a$ '. The next sentence is "We can understand easily". This sentence is incorrect because there is a missing part in the 
sentence, the student did not put the subject 'it' in the sentence. The last sentence is "He can drink glass of milk". This sentence is incorrect because there is a missing part in the sentence. The student forgot the use of article 'a'.

The sentence above should be like this following sentences. The bold words are correction of the error.

1. I think physical exercise is difficult because $I$ hate that

2. What do you think about Agung dika?

3. I think gung dika is a handsome boy

4. We can understand it easily

5. He can drink a glass of milk

\section{Addition}

From 61 error made by the student, 7 error are categorized as addition error. The addition errors are divide into three subcategories; regularization, double marking, and simple addition.

a. Regularization

Regularization is the first subtype of addition error that typically apply to the class of linguistic items, such as the class of main verb or the class of noun. Here are several examples of the error that were made by the students.

1). Do you understanding?

2). What do you think it science easier or difficult?

The first sentence is "do you understanding?". This sentence is incorrect because the student put ing in the word understand, the sentence should be "Do you understand?". The next sentence made by the student is "What do you think it science easier or difficult?". This sentence is incorrect because the student put - er in the word easy, the sentence should be "What do you think is science easy or difficult?" b. Double Marking

Double marking is the second subtype of addition errors. It is defined as the failure to delete certain items which are required in some linguistic construction but not in others.

Here are several examples of the error that were made by the students.

1). Attention please, are we are ready to learn English?

2). Do you do understand of about what the teacher ask to do?

The first sentence is "Attention please, are we are ready to learn English?". This sentence is incorrect, because in this sentence the student used double "are" in the sentence. This sentence should be "Attention please, are we ready to learn English?". The second sentence is "Do you do understand of about what the teacher ask to do?". This sentence is incorrect, because in this sentence the student used double "do" in the sentence. This sentence should be "Do you understand of about what the teacher ask to do?"

c. Simple addition

Simple addition is the last subtype of addition errors. If addition error is not a double marking or regularization, it is called simple addition.

1) Noval, what a do you think about febri?

2) Fatimah can a sing very loudly

3) He can a wash clothes

For the first sentence is "Noval, what a do you think about Febri?". This sentence is incorrect because the student put article ' $a$ ', in the front of the verb: 'do'. In this context the article ' $a$ ' has no meaning. This sentence should be "Noval, what do you think about Febri?". The second sentence is "Fatimah can a sing very loudly". This sentence is incorrect because the students put article 'a' in front of a verb. This sentence should be "Fatimah can sing very loudly". The last sentence is "He can a wash clothes". This sentence is incorrect because the students put article ' $a$ ' in front of a verb. This sentence should be "He can wash clothes". For the simple addition the students made the same errors by the using of article "a", the students adds extra article "a" in sentence.

\section{Misformation}


The researcher found from 61 error that made by the student, 4 error that made by the student are categorized as misformation. There are two types of misformation errors; Archi-form, and Alternating a. Archi form

Archi form, which is also known as 'misselection', is the selection of one number of a class of form to represent others in the class. Here are several examples of the error that was made by the students.

1). what a amazing boy

2). Rani is an beautiful girl

The first sentence is 'what a amazing girl'. This sentence is incorrect because in this sentence the student made the error by misselection of article ' $a$ ', 'What a amazing boy' this sentence is incorrect, and this sentence should be 'What an amazing boy'. The second sentence is 'Rani is an beautiful girl' This sentence is incorrect because in this sentence the student made the error in the use of article 'an'. This sentence should be "Rani is a beautiful girl".

b. Alternating Form

Another of subtypes in the category of misformation is called as alternating forms, which they define as fairly free alternation of various members of class with each other. Here is the example of the error that was made by the students.

1). I think he is a smart

The sentence is "I think he is a smart". This sentence is incorrect because in this the sentence the subject "he" should be "she" because the subject in this sentence is a girl and the sentence should be "I think she is a smart"

\section{Misordering}

Misordering errors are the incorrect placement of a morpheme or group of morpheme in utterances. The researcher found from 61 error that made by the students, 11 error made by the students are categorized as Misordering. Here are the examples of the error made by the students.

1. "What expensive your bag"

2. "What a expensive your bag"

3. "What a expensive bag these"

4. "What are you think this expensive bag"

5. "What it is bag expensive?"

6. "What a expensive this bag"

7. "What expensive it bag"

8. "What expensive this bag"

9. "What a expensive bag"

10. "What a expensive bag or not"

In the sentences number $1-10$, the teacher told the student to make sentence about showing appreciation, the teacher told the students to showing appreciation to the bag. All the sentences that made by the students are wrong, after giving chance to the student the teacher told the correct sentence to the student. The correct sentence is "what an expensive bag".

From the research data, it was found that omission was the highest percentage of students errors made in speaking. Omission is the error which is characterized by the absence of an item that must appear in a well-formed utterance. The errors made by the students mostly about deletion of correct linguistic words, morphemes, and phrase. In this research the errors of omission can be caused by the minimum knowledge about the right structure in English. Because of the lack of knowledge about the structure, the students may lose the structure, as they are able without paying attention to the right role. The students committed 38 errors or 62,30\% out of the whole errors. That result is in line with Alfiyani (2013) and Safrida (2016) who found that the error of omission was the most error that committed by the students. It is quite ddifferent compared with the result of study conducted by Danurwindo (2014). In his research, omission was in the second highest percentage which reaches $42 \%$ from the total of errors.

It also found that those error are caused by the absence of a suffix $-e d$ of a past participle, an article and a singular and plural marker -s/es of a noun and verb. The students often make error in the use of "to be" to make sentence in simple present tense and many of them still omit "to be" to compose the sentence in explaining nominal sentence. It may be caused by the lack of knowledge or bad memorizing 
of "to be" in simple present tense. In the other hand, sometimes, in simple present uses s/es; unless the students omit "s/es" to construct verbal sentence particularly in the third singular person or singular noun.

The second highest percentage of student's errors was misordering. The student committed 11 errors or $18,04 \%$. This error comprised the incorrect placement of a morpheme or group of morpheme. That result is different compared with Alfiyani (2013), Danurwindo (2014), and Safrida (2016)who founded that misordering is the lowest percentage error commited by students in their studies.

The third percentage of students' error was Addition. The students committed 9 error or $14,75 \%$, on their speaking. The errors were characterized by the presence of new structure of morpheme or phrases in a correct linguistic form. The addition errors are divided into three subcategories; regularization, double marking, and simple addition. The highest percentage of addition errors were found in the research data was double marking. The students committed this error as 4 times. This error is caused by the failure to delete certain items which are required in some linguistic construction. The second biggest percentage that the students made in addition errors was Simple addition. The students committed this error as 3 times. Simple addition errors characterize all addition errors. It is the use of an item which should not be appeared in a well-formed utterances. The lowest percentage of addition errors that is found in the research data was Regularization errors. The students committed this error 2 times. This error is caused by the failure to delete certain items which are required in some linguistic construction.

The lowest percentage of student's errors was misformation. The student committed 3 errors or $4,91 \%$ Misformation errors comprised the use of the wrong form of the morphemes or structure. It occurs when the learner supplies something although it is incorrect. There are two types of misformation errors; Archi-form, and Alternating. From the research data, it was found the Archi-form as the biggest errors the students made in the category of Misformation. Archi-forms errors are the selection of one number of a class of forms to represent others in the class is common characteristic of all stages of second language acquisition. The errors of misformation can be caused by the minimum knowledge about the pattern of such structure in language. That result is different compared with Alfiyani (2013) and Sfrida (2016) who founded that misforamation was the second highest percentage with $31.76 \%$ and $29 \%$ out of the total number of the grammatical errors. Even Danurwindo (2014) in his research founded that misformation was the highest percentage which reaches $47 \%$ from the total errors.

From the frequencies of all type of those errors, it was concluded that the students were still committed errors on omission, misformation, addition, and misordering errors. The result of the classification shows that the errors occur in all of the classification of error based on the theory from Dulay, at.al (1982).

\section{CONCLUSION}

Based on the analysis, it can be concluded that: There are some grammatical errors of the eight grade students of SMP Negeri 4 Singaraja in the academic year 2015/2016. The data ware presented in ommition, addition, misformatin and misordering. From 115 sentences that students made there are 61 error that made by the students. The highest frequency of error that made by the student is omission with percentage $62,30 \%$, the second is incorrect structure with percentage $19,67 \%$, the third is addition with percentage $9,84 \%$ and the last is incorrect choice with percentage $8,19 \%$. From the frequencies of the type of those errors above, it was concluded that the students were still committed errors on omission, misformation, addition, and misordering errors.

From the result of this study, some suggestions will hopefully provide more insight into the learning of speaking and give a new idea for better teaching and learning process. The first suggestion is intended for the teachers who are competent to create good atmosphere to facilitate teaching and learning process. It can be suggested that the teachers should be aware on grammatical errors in speaking, thus they can recognize their students' difficulties in speaking so they will pay more attention to the errors made by the students and the causes of the errors in speaking. It is also expected that the teacher can enhance the method in teaching grammar so that the students are motivated to improve their speaking. The second is for the English students who are interested in improving their speaking skill, thus they can be aware to their speaking. The result of this study will show the learners in what aspect of grammar which was difficult for them. By paying more attention, the learners are expected to increase their knowledge on English grammar, thus they will be aware of the errors they made and sources of the 
errors. The learners are expected to develop their speaking proficiency to eliminate or at least reduce those errors. The last is for further researchers who will conduct a research related to this research study. It is expected that the result of the study can give an informative input about grammatical error analysis or other topics related to errors. The researcher believes that there are still many phenomena that can be revealed in this research study. The researcher expects that this result of study can inspire other researchers to conduct the research related to grammatical errors analysis to enrich the existing study.

\section{REFERENCES}

Alfiyani.2003. An Analysis of Grammatical Errors in writing Among The Second Semester Students of English Department of Yogyakarta State University in Academic Year 2011/2012.Yogyakarta: Yogyakarta State University

Brown,D. 2001. Teaching by Principles- An Interactive Approachto Language Pedagogy. Longman: San Francisco State University.

Byrne, D. 1997. Teaching Oral English. Edinburgh: Longman Limited.

Cameron, L.2001. Teaching Languages to Young Learners. Cambridge: Cambridge University Press.

Clark, Herbert and Clark, Eve, Psychology and Language: An Introduction to Psycholinguistics, New York: Harcourt B. Jovanovic Inc.., 1997

Danurwindo.2014.Gramatical Error Analysis in Speaking of the Second Semester English Student of IAIN TulungAgung Academic year 2013-2014. TulungAgung: IAIN

Dulay, H., Burt, M., Krashen S. (1982). Language Two. Oxford: Oxford University, Inc

Gopur.2008.Error Analysis on Student SpeakingPerfomance.Jakarta:Universitas Islam Negeri.

Hughes, A. 1989. Testing For Language Teachers. New York: Cambridge University Press

Hornby, A.S. 1987. Oxford Advanced Learner's Dictionary of Current English: Oxford University Press.

Lock, G. (1997). Functional English Grammar: an Introduction for Second Language Teachers. Cambridge: Cambridge University Press.

Marcel.1853.Language as a Means of Mental Culture and International Communication; or, Manual of theTeacher and the Learner of Languages (London: Chapman and Hall). Two volumes

Moleong, J Lexy, Prof. Dr. 2009, Metode Penelitian Kualitatif. Bandung: PT. Remaja Rosdakaya

Nunan, D. 1999. Second Language Teaching and Learning. Boston: Heinle\&Heinle Publisher.

Richards, J. C. 2008. Teaching Listening and Speaking: From Theory to Practice. Cambridge: Cambridge University Press

Richards, J. C. 2010. Language Teaching and Applied Linguistics .Malaysia: Longman Group UK Limited.

Safrida.2016.Gramatical Errors: An Analysis in Speaking Produce by EFL Ungraduated Studentsl.Banda Aceh: Research in English and Education (READ) Journal.

Ur, P. 1996. A Course in Language Teaching: Practice and Theory. Cambridge: Cambridge University Press.

Yorkey, R. 1990. Study skill for students of English as a second language. New York: MC. Grow Hill.

Widdowson, H.G. (1995). Teaching Language as Communications. Hongkong: Oxford University Press. 